\title{
Rutin ameliorates cigarette smoke mediated lung inflammation in a mouse model of chronic obstructive pulmonary disease via regulating the levels of tumor necrosis factor- $\alpha$, interleukin-8 and PAF
}

Juan Chen, Jinyu Su, Lingyun Dong, Zhiyu Bai, Yufeng Liu, Hongju Bao, Yanfang Lu, Yajuan Wu

Department of Respiratory and Critical Medicine, Affiliated Wujiang Hospital of Nantong, University, Suzhou, China

Submitted: 3 February 2020

Accepted: 26 February 2020

Arch Med Sci

DOI: https://doi.org/10.5114/aoms.2020.95874

Copyright @ 2020 Termedia \& Banach

\section{Abstract}

Introduction: Rutin is a plant-derived flavonoid. In the present work we screened the activity of rutin in a cigarette smoke induced lung disease mouse model of chronic obstructive pulmonary disease (COPD).

Material and methods: The mice were subjected to cigarette smoke for two weeks for inducing COPD simulating lung inflammation. Two hours prior to exposure to cigarette smoke, the mice were treated with rutin via the oral route. After treatment, the mice were assessed for profiling of cytokines and infiltration of immune cells in the bronchoalveolar fluid and histological alterations in the lungs. Roflumilast, an anti-COPD drug, was used as a positive control for comparing the efficacy of rutin.

Results: The results of the study suggested that the treatment with rutin inhibited the inflow of macrophages, lymphocytes and neutrophils significantly in the airway. It was also observed that the treatment with rutin significantly decreased tumor necrosis factor- $\alpha$, interleukin- 8 and platelet activating factor levels in the bronchoalveolar lavage fluid compared to the cigarette smoke exposed group. Interestingly, the findings of our study were parallel to the positive control RFL included in the experiment in the treated mice.

Conclusions: The findings suggested that rutin exerts a protective effect against cigarette smoke mediated COPD-like lung inflammation. Hence rutin may be a novel therapeutic agent for treating inflammatory conditions in lungs such as COPD.

Key words: rutin, chronic obstructive pulmonary disease, cigarette smoke, lung disease, tumor necrosis factor- $\alpha$, interleukin-8, platelet-activating factor.

\section{Introduction}

According to the World Health Organization (WHO) chronic obstructive pulmonary disease (COPD) is one of the most dangerous killers worldwide and ranks $3^{\text {rd }}$ in the list among all the diseases. It has been estimated that more than 5 million peoples will be affected in the next 3 decades [1]. Chronic bronchitis, constricted airway remodeling and emphysema are the main features of COPD, but the main factor contributing to COPD-mediated deaths is the remittance of acute inflam-

\author{
Corresponding author: \\ Yajuan Wu MS \\ Department \\ of Respiratory and \\ Critical Medicine \\ Affiliated Wujiang \\ Hospital of Nantong \\ University \\ Suzhou, China \\ E-mail: BrianLeblancmej@ \\ yahoo.com
}


mation episodes [2-5]. Recently smoking of cigarettes has been identified as one of the most critical risk factors contributing to COPD-related deaths $[6,7]$. Numerous studies have confirmed and established a stable animal model of COPD by continuously exposing animals to cigarette smoke for more than 180 days [8], but recently combining lipopolysaccharides (LPS) for inducing inflammation and hypersecretion of mucus is becoming predominant [9]. It has been reported that cigarette smoke along with LPS leads to over-expression of proinflammatory cytokines such as interleukin (IL) $1 \beta$, tumor necrosis factor- $\alpha$ (TNF- $\alpha$ ), IL- 6 and interferon- $\gamma$ (INF- $\gamma$ ). In COPD the inflammation of airways is mediated by neutrophils and not by eosinophils, which is evidenced by presence of a higher number of neutrophils in bronchoalveolar lavage (BAL) fluid [10]. Currently a number of synthetic agents such as steroids and NMDA inhibitors are used for treating COPD but the use of these agents is associated with adverse effects; hence alternate herbal agents are of utmost importance. Cigarette smoke mediated COPD is characterized by the presence of inflammation, vascular remodeling, smooth muscle hypertrophy and emphysema [11].

Rutin is a plant-derived flavonoid obtained primarily from citrus fruits [12]. Rutin shows a wide range of actions such as antioxidant, anticancer, anti-diabetic and anti-inflammatory properties [13]. In addition, rutin has significantly less toxicity compared to other bioflavonoids. Also it is potent as it is non-oxidizable and hence it is the safest among all the flavonoids. A previous report evidenced that when combined with vitamin $\mathrm{C}$ rutin demonstrated a protective effect in lung injury [14]. However, there are no reports indicating use of rutin in cigarette smoke induced COPD. Looking into the beneficial role of rutin in lung injury here we screened the anti-inflammatory effects of rutin on inflammation in lungs in a mouse model of cigarette smoke induced COPD and the mechanism involved.

\section{Material and methods}

\section{Reagents and chemicals}

Rutin hydrate HPLC grade was procured from Sigma Aldrich USA. It was solubilized in phosphate buffered saline (PBS). Tween-20, fetal bovine serum (FBS), and coating buffer were obtained from Thermo Fisher, USA. Roflumilast (RFL), an anti-inflammatory drug, was used as a positive control which was obtained as a gift sample from the pre-clinical department of Affiliated Wujiang Hospital of Nantong University China. RFL was dissolved in PBS. All the other reagents and chemicals used were of AR grade.

\section{Animal groups, conditions and treatments}

For the present study we used female BALB/C mice aged between 6 and 7 weeks; each group comprised 6 animals. The animals studies were approved by the institutional animal ethical review board of the Affiliated Wujiang Hospital of Nantong University, China; the approval number was NU147R. The animals were exposed to fresh or cigarette smoke air in a chamber supplied by Live cell Inst., South Korea. For the exposure protocol, all the animals were subjected to fresh air or cigarette smoke (6 units/day for 2 weeks); each cigarette smoke exposure lasted for 30 min with an interval of $5 \mathrm{~min}$.

The treatment groups were group 1: control group (Fresh air exposed); group 2: cigarette smoke exposed group (CS group); group 3: RFL group (positive control group); group 4: CS + rutin (200 mg/kg); group 5: CS + rutin (300 mg/kg) and group 6: CS + rutin $(400 \mathrm{mg} / \mathrm{kg})$. The treatment with rutin lasted from the $5^{\text {th }}$ day to the $13^{\text {th }}$ day. On the $14^{\text {th }}$ day (24 $\mathrm{h}$ after the last exposure) the animals were sacrificed and the lungs were collected; also the bronchoalveolar lavage fluid was collected for analysis. The experiments were repeated twice.

\section{Analysis of bronchoalveolar lavage fluid}

After the study protocol, $24 \mathrm{~h}$ after the last exposure, the animals were killed by cervical dislocation. For collecting the bronchoalveolar cells, the lungs of animals were flushed slowly with PBS using injection and the flushed fluid was collected by cannula from the tracheal portion. The cells collected in the fluid were counted using a hemocytometer; further for analyzing the differential cell counts, the fluid was spread on slides by the process of cytocentrifugation for $3 \mathrm{~min}$ at $300 \mathrm{rpm}$ followed by staining (Diff-Quick). After this the bronchoalveolar fluid was centrifuged at $10000 \mathrm{rpm}$, and the obtained supernatant was frozen and stored at $-80^{\circ} \mathrm{C}$.

\section{ELISA study of expression of TNF- $\alpha$, PAF and IL-8 in bronchoalveolar lavage fluid}

The total protein levels were estimated by a protein estimation kit (Thermo Fisher USA). The levels of TNF- $\alpha$, IL- 8 and platelet-activating factor (PAF) were measured by ELISA kit (Thermo Fisher USA). For the analysis a 96-well plate was incubated with anti-rat IL-8, PAF and TNF- $\alpha$ monoclonal antibodies for $12 \mathrm{~h}$ at $4^{\circ} \mathrm{C}$ in coating buffer. The plates were washed with $0.05 \%$ Tween-20 PBS solution and blocked with fetal bovine serum 5\% for $1 \mathrm{~h}$ at $25^{\circ} \mathrm{C}$. After this, the bronchoalveolar lavage fluid $(100 \mu \mathrm{l})$ was stored at room temperature for $1 \mathrm{~h}$. After this the anti-rat TNF- $\alpha$, IL-8 and PAF monoclonal secondary antibodies were incubated in PBS with $5 \%$ FBS for $1 \mathrm{~h}$. Finally, the plates were 
exposed with TMB solution for 20 min and the process was halted using a stop solution. The samples were measured for optical density in a microplate reader (Thermo Fisher USA) at $450 \mathrm{~nm}$.

\section{Histopathology of lung tissue}

At the end of the study the animals were euthanized and lung tissues were harvested for histopathological analysis. The lower lobes of lung tissues were used for the study; the lungs were filled with paraformaldehyde (4\%) solution. The lung tissues were then dehydrated and fixed in paraffin. The embedded tissues were sliced into sections of $4 \mu \mathrm{m}$ on a rotary microtome; the sections were mounted on glass slides, deparaffinized and subjected to hematoxylin and eosin (H\&E) staining. The tissue sections were analyzed for peri-bronchial inflammation as reported earlier [15]. The sections of tissue were stained using periodic acid Schiff (PAS) staining for analyzing the hyperplasia in the goblet cells. The PAS positive stained cells among the total epithelial cells and in the epithelium were recorded. For evaluating the air space in the lungs morphometric analysis was done; tissue sections having the maximum parenchyma cross sections were selected, analyzed and imaged using image scanning software as described earlier [16].

\section{Statistical analysis}

All the results are presented as mean \pm \%RD. All the statistical analysis was done using GraphPad prism (version 5) software (USA). The significance of differences between the groups was determined by performing one-way ANOVA and the Newman-Keuls multiple comparison test. Values of $p<0.05$ were regarded as significant.

\section{Results}

Rutin decreased the numbers of total cells and inflammatory cells in bronchoalveolar lavage fluid

We assessed the anti-inflammatory effect of rutin at three different doses (200, 300 and $400 \mathrm{mg} / \mathrm{kg}$ of body weight) on cigarette smoke induced COPD. It was evidenced that rutin failed to show significant effect at $100 \mathrm{mg} / \mathrm{kg}$ dose, but a dose of $300 \mathrm{mg} / \mathrm{kg}$ showed a significant decrease in count of leukocytes, lymphocytes, neutrophils and macrophages in the bronchoalveolar lavage fluid against the cigarette smoke group (Table I). For establishing the optimum dose of rutin we performed a separate study at 3 different doses of rutin, i.e. $200 \mathrm{mg} / \mathrm{kg}, 300 \mathrm{mg} / \mathrm{kg}$ and $400 \mathrm{mg} / \mathrm{kg}$ of body weight. It was observed that the cigarette smoke treated group demonstrated an elevated number of total leukocytes, lymphocytes, macrophages and neutrophils compared with the animals exposed to fresh air (control group). It was observed that the treatment group rutin $200 \mathrm{mg} / \mathrm{kg}$, $300 \mathrm{mg} / \mathrm{kg}$ and $400 \mathrm{mg} / \mathrm{kg}$ or RFL showed a significant decrease in number of total lymphocytes, macrophages, leukocytes and neutrophils in the bronchoalveolar lavage fluid compared to those exposed to cigarette smoke (Figure 1).

Rutin suppressed the expression of TNF- $\alpha$, IL-8 and PAF in bronchoalveolar lavage fluid of cigarette smoke exposed mice

TNF- $\alpha$, IL- 8 and PAF are identified to be pro-inflammatory cytokines; all of them are involved in inflammatory disorders such as asthma [17]. PAF is reported to enhance the monocytes' toxicity [18]. For studying the anti-inflammatory activity of rutin in lung tissues, the bronchoalveolar lavage fluid was collected and was evaluated for expression of these pro-inflammatory cytokines and chemokines. It was observed that the cigarette smoke exposed mice had significantly increased levels of IL-8, TNF- $\alpha$ and PAF in the bronchoalveolar lavage fluid compared to the animals exposed to fresh air. The positive control group receiving treatment with RFL exhibited decreased expression of TNF- $\alpha$ and IL- 8 compared to negative control animals. However, the RFL-treated mice did not show a decrease in the levels of PAF. Rutin at doses of 200 and $300 \mathrm{mg} / \mathrm{kg}$ body weight demonstrated decreased TNF- $\alpha$ and IL-8 levels in the bronchoalveolar lavage fluid compared to negative control mice. However, suppression of levels of PAF was observed only in mice treated

Table I. Analysis of cells in bronchoalveolar lavage fluid

\begin{tabular}{|c|c|c|c|c|c|c|}
\hline $\begin{array}{l}\text { Cells } \\
{\left[\times 10^{4} / \mathrm{ml}\right]}\end{array}$ & Control & $\begin{array}{l}\text { Cigarette } \\
\text { smoke } \\
\text { exposed }\end{array}$ & $\begin{array}{c}\text { Cigarette } \\
\text { smoke + RFL }\end{array}$ & $\begin{array}{c}\text { Cigarette } \\
\text { smoke + rutin } \\
(200 \mathrm{mg} / \mathrm{kg})\end{array}$ & $\begin{array}{c}\text { Cigarette } \\
\text { smoke + rutin } \\
(300 \mathrm{mg} / \mathrm{kg})\end{array}$ & $\begin{array}{c}\text { Cigarette } \\
\text { smoke + rutin } \\
(400 \mathrm{mg} / \mathrm{kg})\end{array}$ \\
\hline Neutrophils & $0.00 \pm 0.00$ & $0.32 \pm 0.01^{\star \star \star}$ & $0.09 \pm 0.001^{\# \#}$ & $0.29 \pm 0.01$ & $0.16 \pm 0.002$ & $0.05 \pm 0.001^{\# \# \#}$ \\
\hline Macrophages & $2.76 \pm 0.55$ & $12.22 \pm 1.02^{\star \star \star}$ & $6.21 \pm 1.06^{\# \#}$ & $11.10 \pm 1.22$ & $8.11 \pm 1.33$ & $4.65 \pm 1.66^{\# \# \#}$ \\
\hline Lymphocytes & $0.03 \pm 0.001^{\star * *}$ & $0.15 \pm 0.01^{\#}$ & $0.08 \pm 0.001$ & $0.14 \pm 0.003$ & $0.11 \pm 0.005$ & $0.04 \pm 0.001^{\# \# \# ~}$ \\
\hline Total cells & $2.85 \pm 0.012$ & $13.11 \pm 1.11^{\text {***}}$ & $6.59 \pm 0.66^{\#}$ & $12.04 \pm 1.01$ & $8.59 \pm 0.88$ & $5.15 \pm 0.54^{\# \# \#}$ \\
\hline
\end{tabular}

The results are mean \pm SEM, RFL - roflumilast. Statistical analysis was established by one-way ANOVA followed by Newman-Keuls multiple comparison analysis ( ${ }^{* * *} p<0.001$ compared to control, ${ }^{\# \#} p<0.001,{ }^{\# \#} p<0.01,{ }^{\#} p<0.05$ compared to cigarette smoke exposed group). 
A

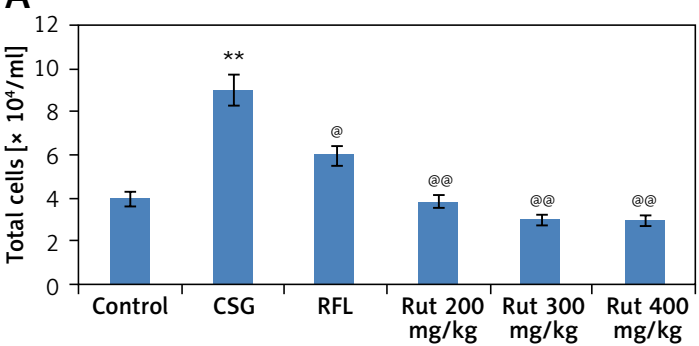

C

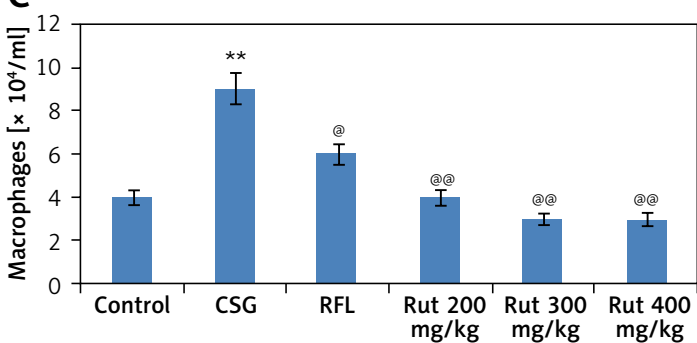

B

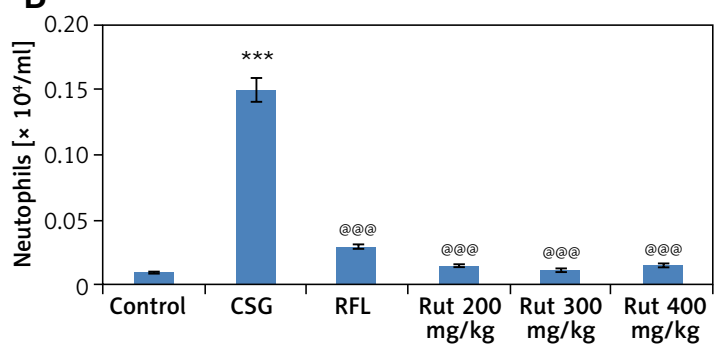

B

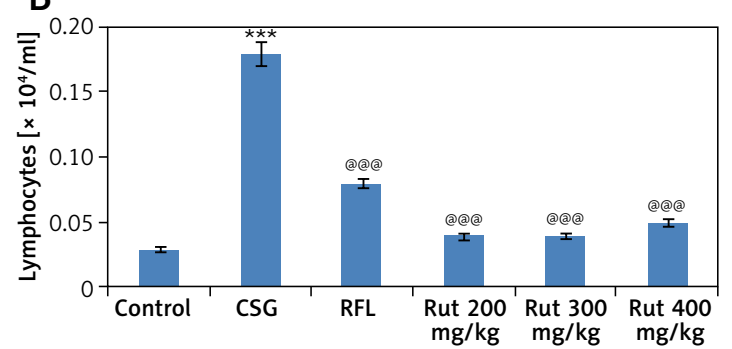

Figure 1. Microscopic findings and cell profiles in bronchoalveolar lavage fluid present in the intrapulmonary bronchi. The animals were sacrificed followed by infusion of phosphate buffered saline in the lungs and collection through a cannula into the trachea. A - Count for total cell numbers, B - total neutrophil count, $\mathbf{C}-$ total count for macrophages, $\mathbf{D}$ - total count for lymphocytes. The results are mean \pm SEM. The statistical significance was established by one-way ANOVA followed by Newman-Keuls multiple comparison analysis $\left({ }^{\star \star *} p<0.001,{ }^{* \star} p<0.01\right.$

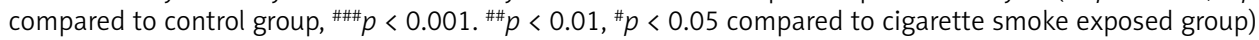

with $300 \mathrm{mg} / \mathrm{kg}$ dose compared to the negative control group; also the treatment showed similar effects on TNF- $\alpha$, IL- 8 and PAF levels in the control fresh air treated group. However, the dose of rutin $100 \mathrm{mg} / \mathrm{kg}$ did not show a significant effect on decreased levels of TNF- $\alpha$, IL- 8 and PAF compared to the negative control group (Figure 2).

\section{Rutin decreases alveolar damage in cigarette smoke exposed mice}

To evaluate whether rutin showed a protective effect on cigarette smoke mediated lung damage,

A

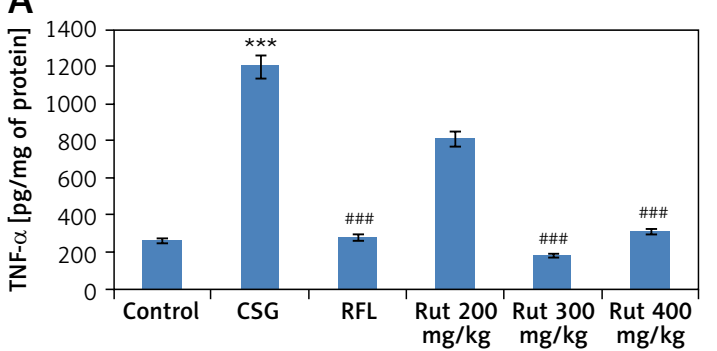

C

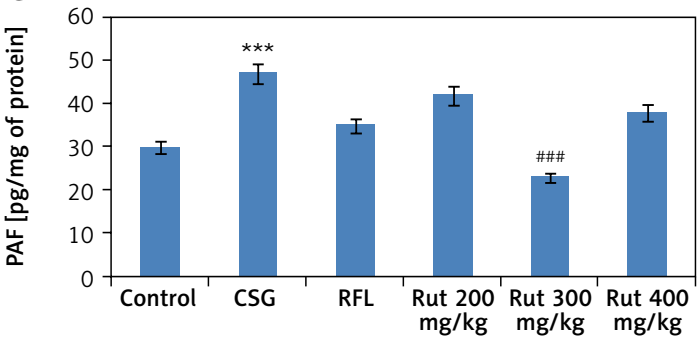

the obtained lung tissue sections were subjected to hematoxylin and eosin staining (H\&E). The outcomes of histopathology of lung tissues showed a similar pattern of cell numbers as observed in bronchoalveolar lavage fluid. There was a significant influx of inflammatory cells into the intraluminal areas as well as in peribronchial layers of the tissue sections of cigarette smoke exposed mice. Treatment with rutin caused a significant decrease in infiltration of inflammatory cells in the lungs of cigarette smoke exposed mice, which was similar to the RFL-treated mice. These findings suggested that treatment with rutin inhib-

B

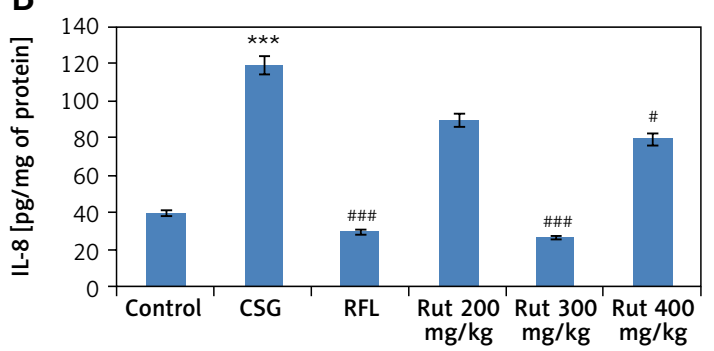

Figure 2. Effect of treatment of rutin on levels of TNF- $\alpha$, IL- 8 and PAF in bronchoalveolar lavage fluid collected from experimental animals. A - Levels of TNF- $\alpha, \mathbf{B}$ - levels of IL-8, C - Levels of PAF as estimated by ELISA. The results are mean \pm SEM. The statistical significance was established by one-way ANOVA followed by Newman-Keuls multiple comparison analysis ( ${ }^{* * *} p<0.001$ compared to control, \#\#\# $p<0.001, " *<0.05$ compared to cigarette smoke exposed group) 
ited the cigarette smoke mediated inflammation in lung tissues similar to the positive control RFL mice (Figures $3 \mathrm{~A}, \mathrm{~B}$ ). Also it was observed that the exposure to cigarette smoke in mice led to enlargement of the airspace. The results of quantitative analysis suggested that the cigarette smoke exposed group showed signs of alveolar damage, which caused an increase in air spaces suggesting an abnormal increase in size of air spaces compared to the rutin-treated group of mice. In contrast the group treated with rutin showed decreased alveolar damage (Figure $3 \mathrm{C}$ ).

Treatment with rutin ameliorates cigarette smoke mediated lung inflammation

For assessing goblet cell hyperplasia, the tissue sections were stained with periodic ac-
id-Schiff (PAS) (Figure 4 A). As reported earlier, the PAS staining positive goblet cells present in the periphery of the epithelium pathway of bronchi were observed primarily in the cigarette smoke exposed mice compared to the control group. However, treatment with rutin decreased the PAS positive cell number around the epithelium of bronchi (Figure 4 B). Cumulatively, the results suggested that rutin exerts a potentially beneficial effect on cigarette smoke mediated inflammation in lungs.

\section{Discussion}

Inflammation is one of the main features of COPD; it is associated with release of various inflammatory mediators such as IL-8, leukotriene B4 and chemokine ligand 6, and these are che-
A

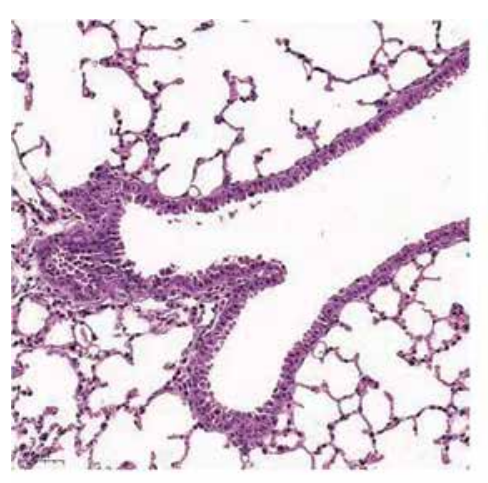

Cigarette smoke + Rut 200 mg/kg

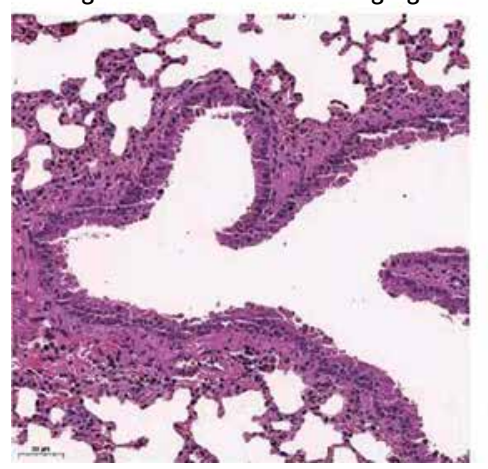

B

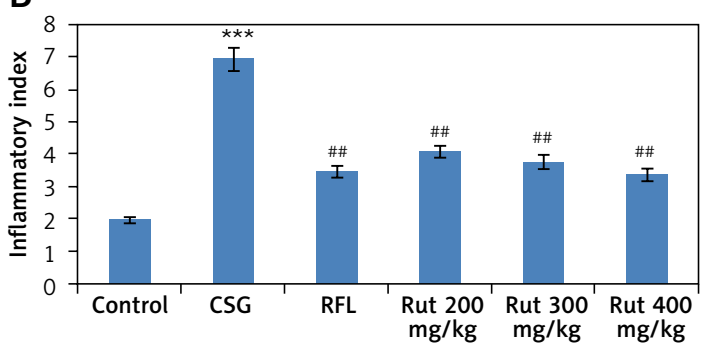

Cigarette smoke exposed

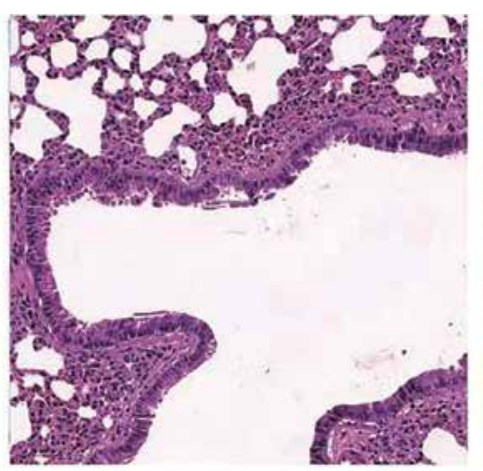

Cigarette smoke + Rut 300 mg/kg

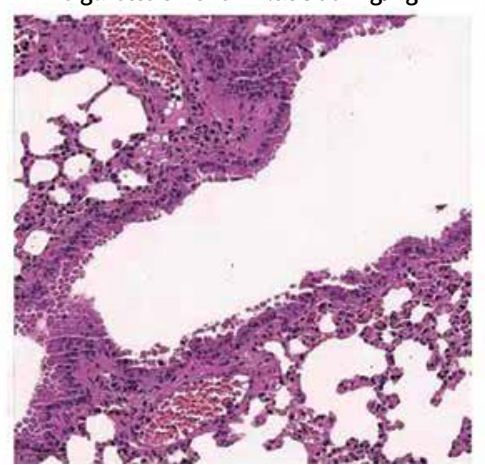

Cigarette smoke + RFL

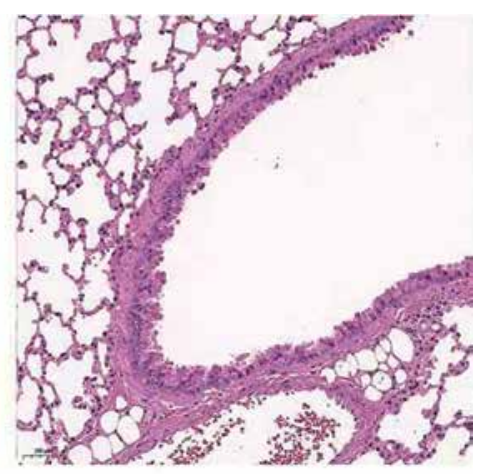

Cigarette smoke + Rut 400 mg/kg

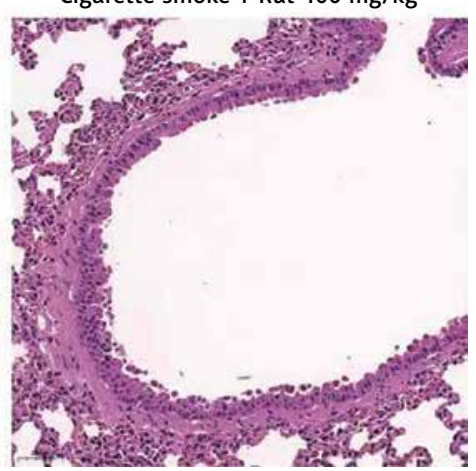

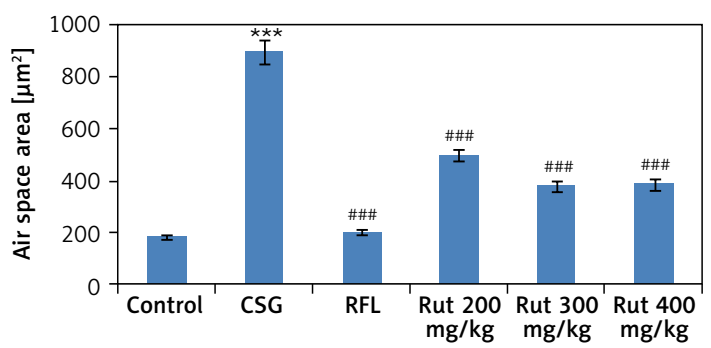

Figure 3. Effect of treatment of rutin on morphological changes in cigarette smoke exposed animals. A - The rats were sacrificed and the right lower lobes of experimental mice were isolated and stained with $H$ \& $E$ staining. B - The air space was recorded using Image-Pro plus 5.1 software. The results are mean \pm SEM. The statistical significance was established by one-way ANOVA followed by Newman-Keuls multiple comparison analysis ( ${ }^{* * *} p<$ 0.001 compared to control, ${ }^{\#} p<0.01$ compared to cigarette smoke exposed mice) 
A

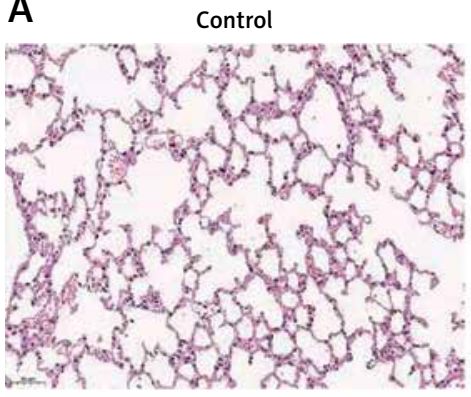

Cigarette smoke + Rut $200 \mathrm{mg} / \mathrm{kg}$

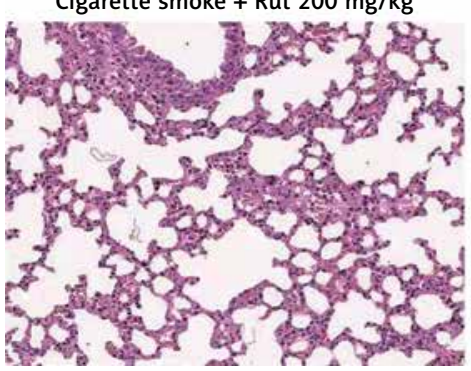

Cigarette smoke exposed

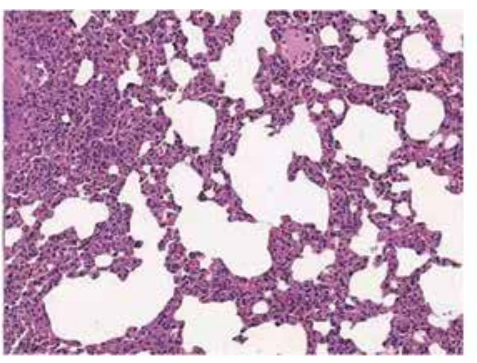

Cigarette smoke + Rut $300 \mathrm{mg} / \mathrm{kg}$

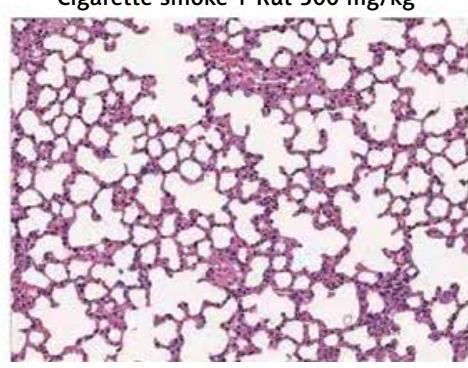

Cigarette smoke + RFL

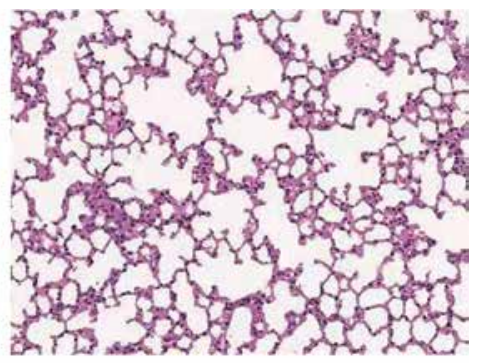

Cigarette smoke + Rut $400 \mathrm{mg} / \mathrm{kg}$

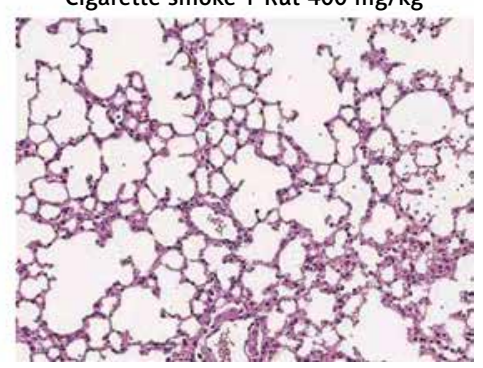

B
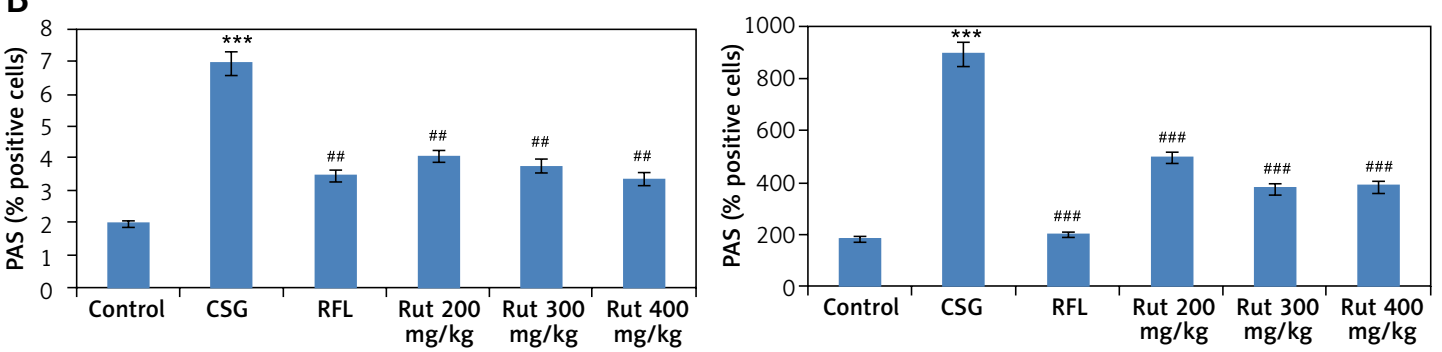

Figure 4. Effect of treatment of rutin on morphological changes in cigarette smoke exposed animals. $\mathbf{A}$ - The rats were sacrificed and the right lower lobes of experimental mice were isolated and stained with $\mathrm{H}$ \& $\mathrm{E}$ staining. B - The air space was recorded using Image-Pro plus 5.1 software. The results are mean \pm SEM. The statistical significance was established by one-way ANOVA followed by Newman-Keuls multiple comparison analysis ( ${ }^{\star * *} p<$ 0.001 compared to control, ${ }^{\# \#} p$ < 0.01 compared to cigarette smoke exposed mice)

moattractants for chemokines and neutrophils such as monocyte chemoattractant protein-1 and macrophage inflammatory proteins responsible for attracting macrophages [19]. Accumulation of neutrophils, dendritic cells and macrophages is seen in COPD [20]. Here, we observed infiltration of inflammatory cells in the bronchoalveolar lavage fluid and in parenchyma of lungs after cigarette smoke exposure. Neutrophils are responsible for inducing tissue damage in COPD by releasing various inflammatory mediators such as elastases and matrix metalloproteinase [21].

In the present study, due to exposure of cigarette smoke in experimental mice the influx of neutrophils resulted in elevated levels of TNF- $\alpha$, IL-8 and PAF in the bronchoalveolar lavage. In addition to this, the exposure to cigarette smoke mediated hyperplasia of goblet cell is linked with induction of bronchitis, which is associated with COPD [22]. Hyperplasia of goblet cells is one of the morphological changes in the lung epithelium; also there are various epithelial alterations which include hypertrophy of sub- mucosal glands along with loss of cells causing decreased mucociliary clearance and formation of mucus [23].

Exposure to cigarette smoke can lead to progression of disorders such as asthma, lung cancer, cardiovascular disorders and COPD. The cigarette smoke contains a number of compounds which include damaging reactive oxygen species which could damage DNA and could activate the PARP enzyme [24].

In the current research, the influx of inflammatory cells in the bronchoalveolar lavage fluid was seen after the exposure to cigarette smoke. Also, the cigarette smoke resulted in accumulation of inflammatory cells in the lung parenchyma, increased secretion of mucus, goblet cell hyperplasia and alveoli enlargement. Here, we observed changes which were very like those observed in patients with COPD [21]. In the study it was observed that after exposing the mice to cigarette smoke the treatment with rutin showed efficacy which was comparable to the positive control group treated with RFL, which is 
currently the commercially available anti-COPD agent [25].

Previously several studies involving molecules from herbal sources have been used in correcting COPD and related disorders. Radix Stemonae is a traditional Chinese medicine used as an anti-tussive agent; recently it was reported to show a protective effect in a COPD model in rats [26]. Asparagus cochinchinensis has been reported to exert a protective effect in asthma [27]. The extract of Schisandra chinensis has been evidenced to show an antitussive effect in cigarette smoke exposed guinea pigs [28]. Rutin is a molecule of the flavonol category; it has been reported to exert various activities such as anti-cancer, anti-inflammatory and anti-tussive. The identified molecular targets of rutin are TNF- $\alpha$, IL- $1 \beta$, PARP, iNOS, IL- 6 and IL- 8 [29]. So looking into the activities and targets of rutin it can be beneficial in correcting inflammatory disorders such as COPD. However, there are no reports exploring rutin in cigarette smoke induced animal models. This is the first time that rutin has been tested for its action in cigarette smoke exposed mice. In the present study rutin at three doses (200, 300 and $400 \mathrm{mg} / \mathrm{kg}$ body weight) decreased the influx of inflammatory cells in the bronchoalveolar lavage fluid significantly. Furthermore, when the histological characters were assessed in the lung tissues, rutin $(300 \mathrm{mg} / \mathrm{kg}$ ) suppressed the influx of neutrophils, lymphocytes and macrophages and the goblet cell metaplasia. In addition, the treatment with rutin also inhibited the thickening of epithelial basement membrane and inflammation of the bronchi. Rutin at a dose of $300 \mathrm{mg} / \mathrm{kg}$ also significantly decreased the IL-8, TNF- $\alpha$ and PAF levels compared to cigarette smoke exposed mice. However, rutin at the dose of 200 $\mathrm{mg} / \mathrm{kg}$ failed to show a significant effect compared to the other two high doses of 300 and $400 \mathrm{mg} / \mathrm{kg}$ on the production of IL-8, TNF- $\alpha$ and PAF.

IL-8, also known as interlukin-8, is a known chemokine secreted by the macrophages, epithelial cells and airway smooth muscles [30]. TNF- $\alpha$ is a pro-inflammatory cytokine which is reported to activate other cytokines such as II-8 and IL-6 [31]. It has also been found to be responsible for increasing the gene transcription of IL-8 [21]. Platelet-activating factor (PAF) is reported to be a potential lipid mediator implicated in disorders such as acute lung injury, asthma and ischemia/ reperfusion injury [32].

In the present work, rutin suppressed the production of pro-inflammatory cytokine in cigarette smoke exposed mice in an acute as well as a chronic lung inflammatory condition. Hence we believe that rutin may steadily act on downstream effects which include infiltration of inflammatory cells and inflammatory mediators. Parallel to this, the histopathological data suggested that treatment with rutin halted the progression of airspace enlargement and also the hyperplasia of goblet cells. The findings showed a beneficial effect of rutin for structural changes of lung tissues in the cigarette smoke induced COPD condition in an animal model.

In conclusion, the findings of the present work provide concrete proof about the treatment with rutin showing beneficial effects against the cigarette smoke mediated inflammation in lungs of mice. The activity against the inflammatory mediators clearly confirms the potential of rutin in treating COPD. However, a detailed study elucidating the mechanism of action of rutin should be done.

\section{Acknowledgments}

This study was supported by Suzhou science and technology development plan (No: SYSD2019044).

Juan Chen and Jinyu Su contributed to this work.equally.

\section{Conflict of interest}

The authors declare no conflict of interest.

\section{References}

1. Dance A. Health impact: breathless, Nature 2012; 489: S2-3.

2. Cottin V, Nunes H, Brillet PY, et al.; Groupe d'Etude et de Recherche sur les Maladies Orphelines P. Combined pulmonary fibrosis and emphysema: a distinct underrecognised entity. Eur Respir J 2005; 26: 586-93.

3. Morse D, Rosas IO, Tobacco smoke-induced lung fibrosis and emphysema, Annu Rev Physiol 2014; 76: 493-513.

4. Barnes PJ. Inflammatory mechanisms in patients with chronic obstructive pulmonary disease. J Allergy Clin Immunol 2016; 138: 16-27.

5. Curtis JL, Freeman CM. Why do we need a nonhuman primate model of smokinginduced COPD? Am J Pathol 2015; 185: 610-3.

6. D'Hulst Al, Vermaelen KY, Brusselle GG, Joos GF, Pauwels RA. Time course of cigarette smoke-induced pulmonary inflammation in mice. Eur Respir J 2005; 26: 204-13.

7. Yoshida T, Tuder RM. Pathobiology of cigarette smoke-induced chronic obstructive pulmonary disease. Physiol Rev 2007; 87: 1047-82.

8. Singanayagam A, Glanville N, Walton RP, et al. A short term mouse model that reproduces the immunopathological features of rhino virus induced exacerbation of COPD. Clin Sci 2015; 129: 245-58.

9. Shin NR, Ko JW, Park SH, et al. Protective effect of HwangRyunHaeDok-Tang water extract against chronic obstructive pulmonary disease induced by cigarette smoke and lipopolysaccharide in a mouse model. J Ethnopharmacol 2017; 200: 60-5.

10. Siafakas NM, Vermeire P, Pride NB, et al. Optimal assessment and management of chronic obstructive pulmonary disease (COPD). The European Respiratory Society Task Force. Eur Respir J 1995; 8: 1398-420. 
11. Cuzic S, Bosnar M, Dominis Kramaric $M$, et al. Claudin-3 and Clara cell $10 \mathrm{kDa}$ protein as early signals of cigarette smoke-induced epithelial injury along Alveolar ducts. Toxicol Pathol 2012; 40: 1169-87.

12. Calabrò M, Tommasini S, Donato $P$, et al. The rutin/beta-cyclodextrin interactions in fully aqueous solution: spectroscopic studies and biological assays. J Pharm Biomed Anal 2005; 36: 1019-27.

13. Hertog $M$, Hollman $P$, Katan $M$, Kromhout D. Intake of potentially anticarcinogenic flavonoids and their determinants in adults in the Netherlands. Nutr Cancer 1993. 20: 21-9.

14. Je HD, Shin CY, Park SY, et al. Combination of vitamin C and rutin on neuropathy and lung damage of diabetes mellitus rats. Arch Pharm Res 2002; 25: 184-90.

15. Choi JM, Ahn MH, Chae WJ, et al. Intranasal delivery of the cytoplasmic domain of CTLA-4 using a novel protein transduction domain prevents allergic inflammation. Nat Med 2006; 12: 574-9.

16. Epaud R, Aubey F, Xu J, et al. Knockout of insulin-like growth factor-1 receptor impairs distal lung morphogenesis. PLoS One 2012; 7: e48071.

17. Ellen MD, William M. Potential role of IL-8, platelet-activating factor and TNF-alpha in the sequestration of neutrophils in the lung: effects on neutrophil deformability, adhesion receptor expression, and chemotaxis. Eur J Immunol 2002; 32: 393-403.

18. Valone FH, Philip R, Debs RJ. Enhanced human monocyte cytotoxicity by platelet-activating factor. Immunology 1988; 64: 715-8.

19. Barnes PJ. Mediators of chronic obstructive pulmonary disease. Pharmacol Rev 2004; 56: 515-48.

20. Huvenne W, Perez-Novo CA, Derycke L, et al. Different regulation of cigarette smoke induced inflammation in upper versus lower airways. Respir Res 2010; 11: 100.

21. Chung KF. Cytokines in chronic obstructive pulmonary disease. Eur Respir J Suppl 2001; 34: 50s-9s.

22. Maestrelli P, Saetta M, Mapp CE, Fabbri LM. Remodeling in response to infection and injury. Airway inflammation and hypersecretion of mucus in smoking subjects with chronic obstructive pulmonary disease. Am J Respir Crit Care Med 2001; 164: S76-80.

23. Cosio MG, Hale KA, Niewoehner DE. Morphologic and morphometric effects of prolonged cigarette smoking on the small airways. Am Rev Respir Dis 1980; 122: 265-21.

24. Kovacs K, Erdelyi K, Hegedus C, et al. Poly(ADP-ribosyl) ation is a survival mechanism in cigarette smoke-induced and hydrogen peroxide-mediated cell death. Free Radic Biol Med 2012; 53: 1680-8

25. Keenan CR, Salem S, Fietz ER, Gualano RC, Stewart AG. Glucocorticoidresistant asthma and novel anti-inflammatory drugs. Drug Discov Today 2012; 17: 1031-8.

26. Wang Z, Yang W, Yang P, Gao B, Luo L. Effect of Radix Stemonae concentrated decoction on the lung tissue pathology and inflammatory mediators in COPD rats. BMC Complement Altern Med 2016; 16: 457.

27. Choi JY, Kim JE, Park JJ, et al. The antiinflammatory effects of fermented herbal roots of asparagus cochinchinensis in an ovalbumin-induced asthma model. J Clin Med 2018; 7: pii: E377.

28. Yang L, Zhong S, Liu XD, Huang CQ, Lai KF. Antitussive effect of Schisandra Chinensis extracts on cigarette smoke exposed guinea pigs and their underlying mechanism. Chest 2016; 149: A353.
29. Wu XJ, Lowes DA, Galley HF, Webster NR. Effects of resceratrol and rutin on secretion of interleukin- 6 and interleukin-8 from human mononuclear cells and polymorphonuclear cells. Chin J N Drugs 2009; 18: 151-4.

30. Bickel M. The role of interleukin-8 in inflammation and mechanisms of regulation. J Periodontol 1993; 64: 456-60.

31. Drost EM, MacNee W. Potential role of IL-8, platelet-activating factor and TNF-alpha in the sequestration of neutrophils in the lung: effects on neutrophil deformability, adhesion receptor expression, and chemotaxis. Eur J Immunol 2002; 32: 393-403.

32. Uhlig S, Göggel R, Engel S. Mechanisms of platelet-ac tivating factor (PAF)-mediated responses in the lung. Pharmacol Rep 2005; 57 Suppl: 206-21. 